\title{
Does physical activity modify the risk of obesity for type 2 diabetes: a review of epidemiological data
}

\author{
Li Qin · Mirjam J. Knol • Eva Corpeleijn • \\ Ronald P. Stolk
}

Received: 10 April 2009/ Accepted: 29 September 2009/Published online: 22 October 2009

(C) The Author(s) 2009. This article is published with open access at Springerlink.com

\begin{abstract}
Obesity and physical inactivity are both risk factors for type 2 diabetes. Since they are strongly associated, it has been suggested that they might interact. In this study, we summarized the evidence on this interaction by conducting a systematic review. Two types of interaction have been discerned, statistical and biological interaction, which could give different results. Therefore, we calculated both types of interaction for the studies in our review. Cohort studies, published between 1999 and 2008, that investigated the effects of obesity and physical activity on the risk of type 2 diabetes were included. We calculated both biological and statistical interaction in these studies. Eight studies were included of which five were suitable to calculate interaction. All studies showed positive biological interaction, meaning that the joint effect was more than the sum of the individual effects. However, there was inconsistent statistical interaction; in some studies the joint effect was more than the product of the individual effects, in other studies it was less. The results show that obesity and physical inactivity interact on an additive scale. This means that prevention of either obesity or physical inactivity, not only reduces the risk of diabetes by taking away the independent effect of this factor, but also by preventing the cases that were caused by the interaction between both factors. Furthermore, this review clearly showed that results can differ depending on what method is used to assess interaction.
\end{abstract}

L. Qin · E. Corpeleijn · R. P. Stolk $(\bowtie)$

Department of Epidemiology, University Medical Center

Groningen, University of Groningen, P.O. Box 30.001,

9700, RB, Groningen, The Netherlands

e-mail: r.p.stolk@epi.umcg.nl

M. J. Knol

Julius Center for Health Sciences and Primary Care,

University Medical Center Utrecht, Utrecht, The Netherlands
Keywords Type 2 diabetes - Obesity - Physical activity · Biological interaction $\cdot$ Statistical interaction

\section{Introduction}

Obesity and physical inactivity are both independent risk factors for type 2 diabetes. The excessive free fatty acid released by adipose tissue leads to a decrease in insulin sensitivity of muscle, fat and liver, which is followed by raised glucose levels, insulin resistance and type 2 diabetes [1-4]. Physical inactivity accelerates the pathogenesis of type 2 diabetes and subsequently leads to excess morbidity and mortality [5].

It has been suggested that obesity and physical inactivity interact with each other. Physical activity may counteract the diabetogenic impact of obesity by reducing fat mass, increasing fat oxidative capability or through other biological pathways, and obesity may be less detrimental to physically fit individuals with or without diabetes [6, 7]. However, the pathophysiological mechanisms are not fully understood. From public health and clinical perspectives, a well understanding of the interaction between obesity and physical activity is important to identify target groups and implement primary prevention strategies for type 2 diabetes.

Interaction refers to a situation where the effect of one risk factor on a certain disease outcome is different across strata of another risk factor. Rothman [8, 9] described two types of interaction: statistical and biological. First, statistical interaction is departure from the underlying form of a statistical model, and it can be assessed by entering a product term in statistical models. Because there are various statistical models, statistical interaction does not have a consistent meaning. For instance, an interaction term in a 
linear regression model, refers to interaction as departure from additivity; an interaction term in a logistic regression model, refers to interaction as departure from multiplicativity [8, 10]. Second, biological interaction is defined as two causes acting in the same sufficient-component model to cause disease. Biological interaction should be assessed as departure from additivity rather than multiplicativity [8, 9]. In epidemiological research, logistic regression or Cox proportional hazards models, which are inherently multiplicative, are often used. In that case, assessment of statistical interaction could lead to different results than assessment of biological interaction (Appendix).

Although the independent effects of obesity and physical activity have been extensively studied, only a small number of studies investigated interaction between obesity and physical activity on the risk of type 2 diabetes. To summarize the evidence for this interaction, we conducted a systematic literature review. Furthermore, since there are two types of interaction, which could give different results, we calculated both statistical interaction and biological interaction for the included studies in our review.

\section{Methods}

\section{Study selection}

A literature search was carried out in PubMed in August 2008. We used the following search terms: (Obesity OR Overweight OR "body mass index" OR "body fat" OR "body weight" OR "abdominal fat") AND ("Physical Activity" OR exercise) AND "Diabetes Mellitus, Type 2 "[Mesh]). We limited our search to studies in humans, studies that were published in the last 10 years (1999-2008) and studies written in English. We also checked the references of the selected articles for additional publications.

We included cohort studies that reported relative risks or incidences of type 2 diabetes. As body mass index (BMI) is a common measure of obesity, studies using BMI to define obesity were included. Studies that used metabolic equivalent score (METs) or the duration or intensity of physical activity to define categories of physical activity were included.

\section{Data extraction}

We extracted the following of all studies: number of patients, age, sex, follow-up duration, method of assessment of obesity and physical activity, the type of stratification, confounders adjusted for, statistical model used, and whether interaction was analysed. Three relative risks of each study were extracted: (1) the relative risk representing the individual effect of obesity (the risk in obese and physically active individuals relative to the risk in normal weight and physically active individuals), (2) the relative risk representing the individual effect of physical inactivity (the risk in normal weight and physically inactive individuals relative to the risk in normal weight and physically active individuals), (3) the relative risk representing the joint effect of obesity and physical inactivity (the risk in obese and physically inactive individuals relative to the risk in normal weight and physically active individuals). Normal weight was defined as $<25 \mathrm{~kg} \mathrm{~m}^{-2}$, obesity was defined as $\mathrm{BMI} \geq 30 \mathrm{~kg} \mathrm{~m}^{-2}$, physically active was defined as $\geq 21.8 \mathrm{MET} \mathrm{h}^{-1}$ week $^{-1}$, and physically inactive was defined as $<2.1 \mathrm{MET}^{-1}$ week $^{-1}$. If studies did not use these exact cut-points, we used the available category in the study which was closest to our definition.

\section{Calculation of interaction}

For the studies that reported the relative risk for the individual effect of obesity, the individual effect of physical inactivity and their joint effect, we calculated statistical and biological interaction as described below.

\section{Statistical interaction}

Consider two dichotomous factors $\mathrm{A}$ and $\mathrm{B}$ as risk factors for a certain disease. $R R_{A}, R R_{B}$ and $R R_{A B}$ denote the relative risks for the independent effect of $A$, the independent effect of B, and the joint effect of A and B. Statistical interaction is then assessed by adding a product term $(\mathrm{A} \times \mathrm{B})$ in a regression model. In logistic regression or a Cox proportional hazards model, the exponential transformation of the regression coefficient of this product term $\left(\beta_{\mathrm{A} \times \mathrm{B}}\right)$ quantifies interaction on a multiplicative scale $\left(\mathrm{INT}_{\mathrm{M}}\right)$. Interaction on a multiplicative scale can also be calculated by using the relative risks of the individual and joint effects of both exposures. $\mathrm{INT}_{\mathrm{M}}$ is,

$\mathrm{INT}_{\mathrm{M}}=\mathrm{e}^{\beta_{\mathrm{A} \times \mathrm{B}}}=\frac{\mathrm{RR}_{\mathrm{AB}}}{\mathrm{RR}_{\mathrm{A}} \cdot \mathrm{RR}_{\mathrm{B}}}$

If $\beta_{\mathrm{A} \times \mathrm{B}}=0, \mathrm{INT}_{\mathrm{M}}=1, \mathrm{RR}_{\mathrm{AB}}=\mathrm{RR}_{\mathrm{A}} \times \mathrm{RR}_{\mathrm{B}}$, there is no interaction as departure from multiplicativity; if $\beta_{\mathrm{A} \times \mathrm{B}}>0$, $\mathrm{INT}_{\mathrm{M}}>1$, there is positive interaction as departure from multiplicativity.

\section{Biological interaction}

Biological interaction can be assessed by calculating the relative excess risk due to interaction (RERI), which was proposed by Rothman [8, 9]. Filling out the independent effect of $A\left(R R_{A}\right)$, the independent effect of $B\left(R R_{B}\right)$, and 
the joint effect of $A$ and $B\left(R_{A B}\right)$ in the formula gives the RERI:

$\mathrm{RERI}=\mathrm{RR}_{\mathrm{AB}}-\mathrm{RR}_{\mathrm{A}}-\mathrm{RR}_{\mathrm{B}}+1$

If RERI $=0$, then $R_{A B}=R_{A}+R R_{B}-1$, there is no interaction as departure from additivity; if RERI $>0$, then $R_{A B}>R_{A}+R_{B}-1$, there is positive interaction as departure from additivity.

The proportion of the combined effect that can be attributed to interaction (AP) is another measure of biological interaction, and can be calculated using the following formula:

$\mathrm{AP}=\frac{\mathrm{RERI}}{\mathrm{RR}_{\mathrm{AB}}}$

If $\mathrm{RERI}=0$, then $\mathrm{AP}=0$, there is no interaction as departure from additivity; if RERI $>0$, then AP $>0$, there is positive interaction as departure from additivity.

\section{Results}

Of 1,158 publications, eight studies met the inclusion criteria. Figure 1 shows the selection process. Participants were mainly white populations from North America and Europe. Four studies had included only women, one study only men, and another three reported both genders (Table 1). All of these studies used stratification, but six studies reported both independent and joint effects [11-16].
In general, obesity was a stronger independent risk factor than physical inactivity for type 2 diabetes. Some studies concluded that the risk of physical inactivity differed between categories of BMI [11-13, 15]. It was suggested that increased physical activity may, at least in part, counteract the detrimental effects of obesity, particularly in obese individuals. However, other studies found that diabetes risk increased dramatically over BMI categories, and the beneficial effect of physical activity was minimal [14, 16-18]. Furthermore, two studies suggested that physical activity may be more beneficial for normal weight than obese individuals [17, 18]. Only three studies formally assessed interaction and two presented that there was no significant $P$ value for interaction between BMI and physical activity in the Cox proportional hazard model [14-16].

Five studies reported the relative risk for the individual effect of obesity, the individual effect of physical inactivity and their joint effect and therefore statistical and biological interaction could be calculated. Table 2 presents these relative risks, the interaction as departure from multiplicativity, and the measures RERI and AP representing interaction as departure from additivity. Interaction on a multiplicative scale $\left(\mathrm{INT}_{\mathrm{M}}\right)$ showed inconsistent results. Two studies [12, 13] had $\mathrm{INT}_{\mathrm{M}}>1$, suggesting positive interaction as departure from multiplicativity; three studies $[11,15,16]$ had $\mathrm{INT}_{\mathrm{M}}<1$, suggesting negative interaction as departure from multiplicativity. This means that the joint effect of obesity and physical inactivity is larger (in two of the studies) or smaller (in three studies) than the product of the individual effects of obesity and physical inactivity.

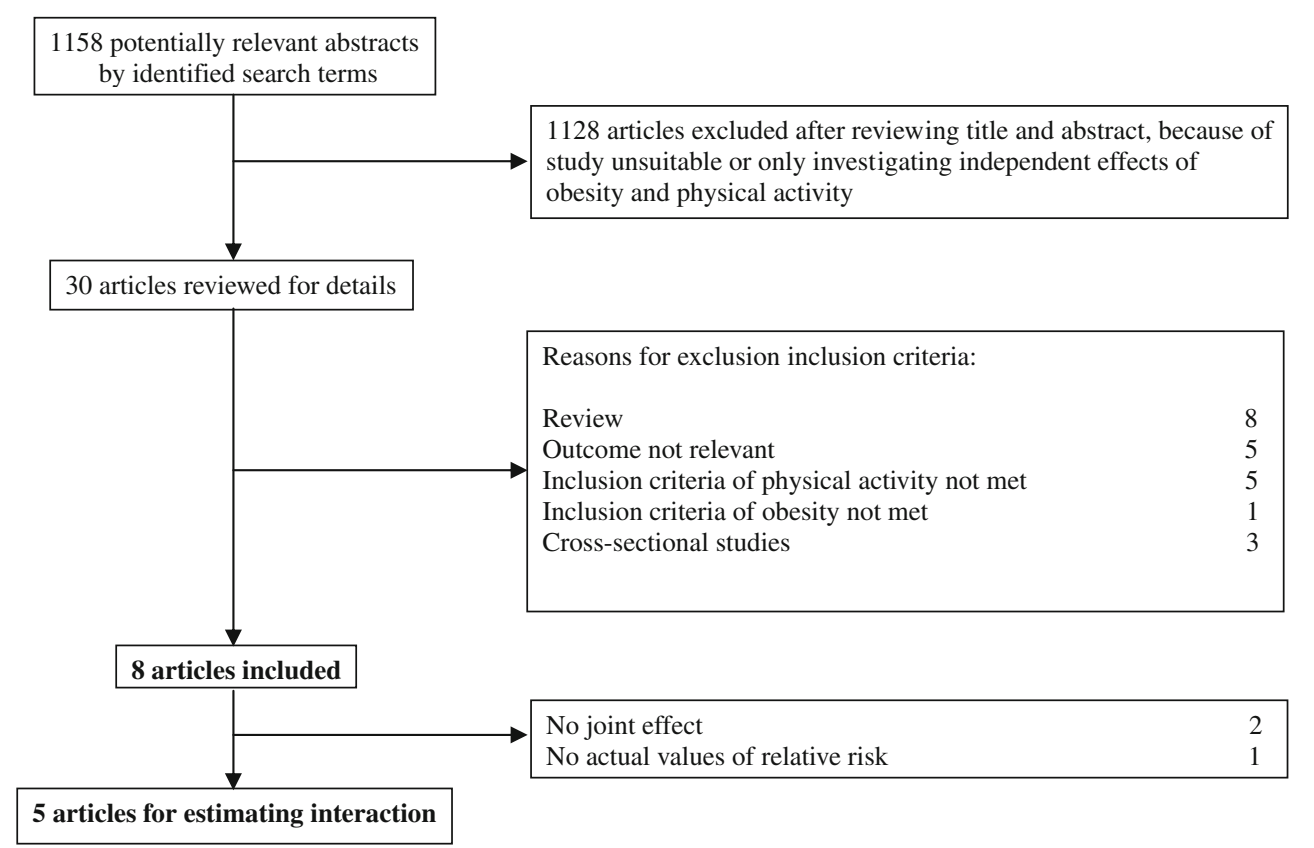

Fig. 1 Flow chart of the articles selection process 


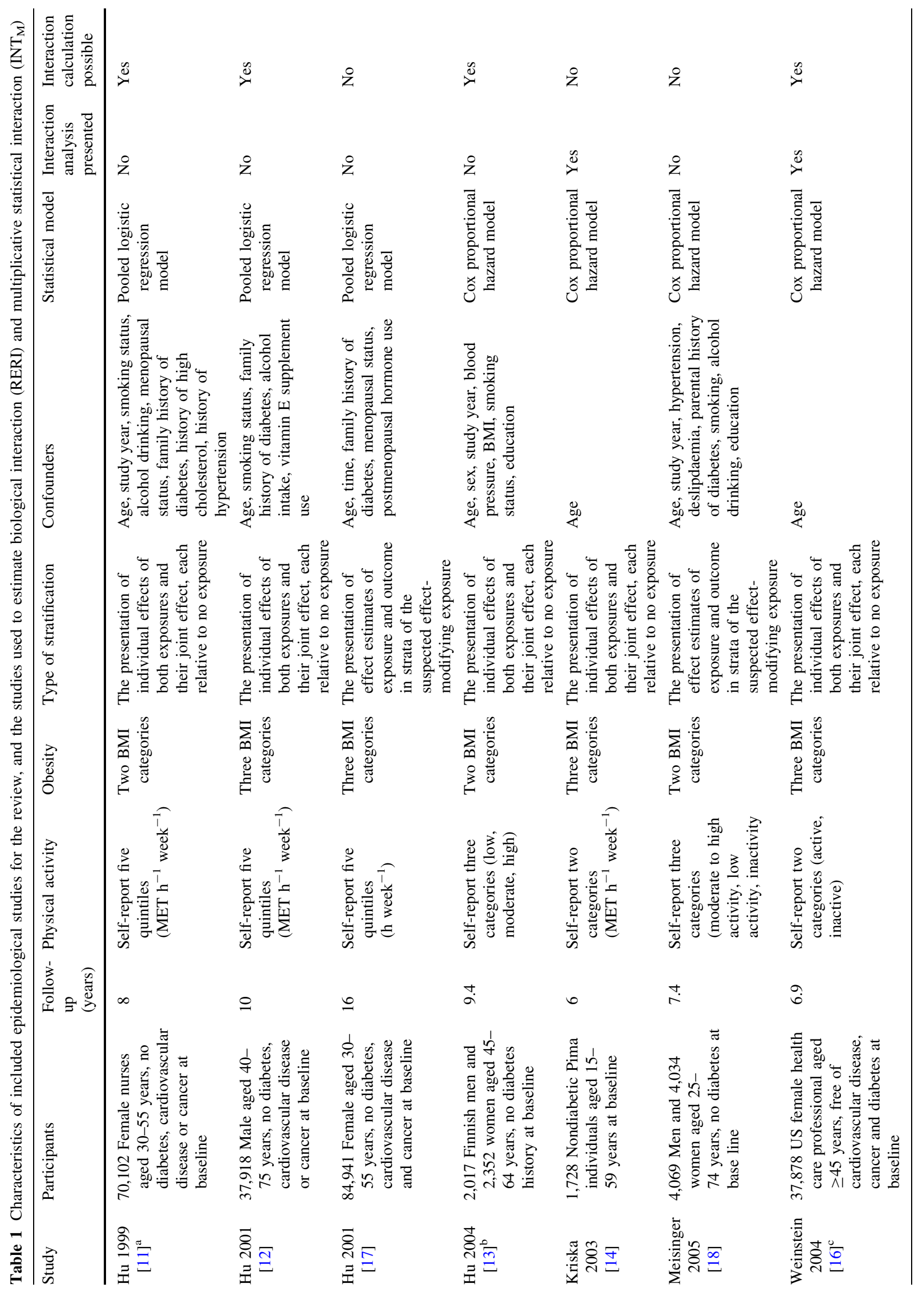




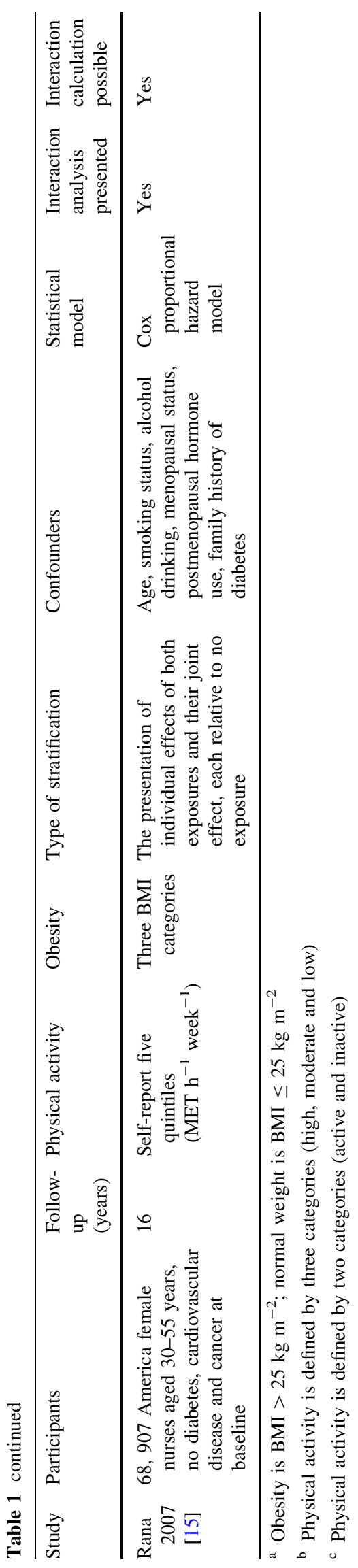

The RERI was larger than zero in all included studies, suggesting positive interaction as departure from additivity. This means that the joint effect of obesity and physical inactivity is larger than the sum of the individual effects of obesity and physical inactivity. When using the study by Rana et al. [15] as an example, the relative risk due to joint exposure $(\mathrm{RR}=16.75)$ was composed by the relative risks due to two individual exposures $(\mathrm{RR}=10.74$; $\mathrm{RR}=2.08$ ), the background relative risk (one as reference category) and the relative excess risk due to the interaction between obesity and physical inactivity (RERI $=4.93$ ). This means that the relative risk of diabetes in inactive obese individuals is 4.93 more than if there was no interaction between these two factors. Furthermore, about $29.4 \%$ of the joint effect could be attributed to the interaction, while only $6.4 \%$ could be attributed to the independent effect of physical inactivity. In all studies, the proportion attributable to the interaction was larger than the individual effect of physical inactivity. Figure 2 illustrates the contribution of obesity, physical inactivity and their interaction to the total effect on the risk of diabetes, which also shows that physical inactivity contributes less than the interaction.

\section{Discussion}

We found eight studies that looked at the joint effect of obesity and physical activity on type 2 diabetes. Three studies analysed whether interaction was present between obesity and physical activity. The results of the stratified analyses presented in the papers varied and did not answer the question whether obesity and physical activity interact. We calculated interaction from the included studies and showed that there was positive interaction on an additive scale, while the results for interaction on a multiplicative scale were inconsistent.

Physical activity may increase insulin sensitivity, glucose disposal and free fatty acids oxidative capability [5]. However, results from intervention studies indicate that exercise has no noticeable effect on glucose regulation and insulin action in obese individuals without additional weight loss $[19,20]$. Exercise is associated with a reduction in subcutaneous and visceral fat beyond weight loss, but the improvement of insulin sensitivity would be small without significant weight loss [19-22]. Furthermore, the additional beneficial effect of exercise on metabolic complications seems only relevant when accompanied by certain amount of weight loss $[19,20,23]$. The positive biological interaction between obesity and physical inactivity support this combined pathophysiology.

All studies in our review showed positive interaction on an additive scale, which is the recommended method to 
Table 2 Estimation of multiplicative statistical interaction $\left(\mathrm{INT}_{\mathrm{M}}\right)$, biological interaction (RERI) and attributable proportion due to biological interaction (AP)

\begin{tabular}{|c|c|c|c|c|c|c|}
\hline Study & $\begin{array}{l}\text { Relative risk } \\
\text { joint effect }\end{array}$ & $\begin{array}{l}\text { Relative risk individual } \\
\text { effect obesity }\end{array}$ & $\begin{array}{l}\text { Relative risk individual } \\
\text { effect physical inactivity }\end{array}$ & $\mathrm{INT}_{\mathrm{M}}^{\mathrm{b}}$ & $\mathrm{RERI}^{\mathrm{c}}$ & $\mathrm{AP}(\%)$ \\
\hline 1. Hu et al. $[13]^{\mathrm{a}}$ & 9.86 & 4.10 & 2.18 & 1.10 & 4.58 & 46.4 \\
\hline 2. Hu et al. $[12]^{\mathrm{a}}$ & 9.87 & 5.62 & 1.12 & 1.56 & 4.12 & 41.7 \\
\hline 3. Rana et al. [15] & 16.75 (13.99-20.04) & $10.74(8.74-13.18)$ & $2.08(1.66-2.61)$ & 0.75 & 4.93 & 29.4 \\
\hline 4. Hu et al. $[11]^{\mathrm{a}}$ & 12.50 & 8.75 & 2.00 & 0.71 & 2.75 & 22.0 \\
\hline 5. Weinstein et al. [16] & $18.6(13.9-24.8)$ & $17.5(12.9-23.9)$ & $1.25(0.91-1.72)$ & 0.85 & 0.85 & 4.6 \\
\hline
\end{tabular}

${ }^{a}$ No confidence interval available

${ }^{\mathrm{b}} \mathrm{INT}_{\mathrm{M}}>1$, positive interaction as departure from multiplicativity; $\mathrm{INT}_{\mathrm{M}}<1$, negative interaction as departure from multiplicativity

c RERI $>0$, positive interaction as departure from additivity

Fig. 2 Illustration of relative risks for the individual effect of physical inactivity, the individual effect of obesity, and the joint effect of obesity and physical inactivity. The difference between the joint effect and the sum of the individual effects is the relative excess risk due to interaction (RERI)

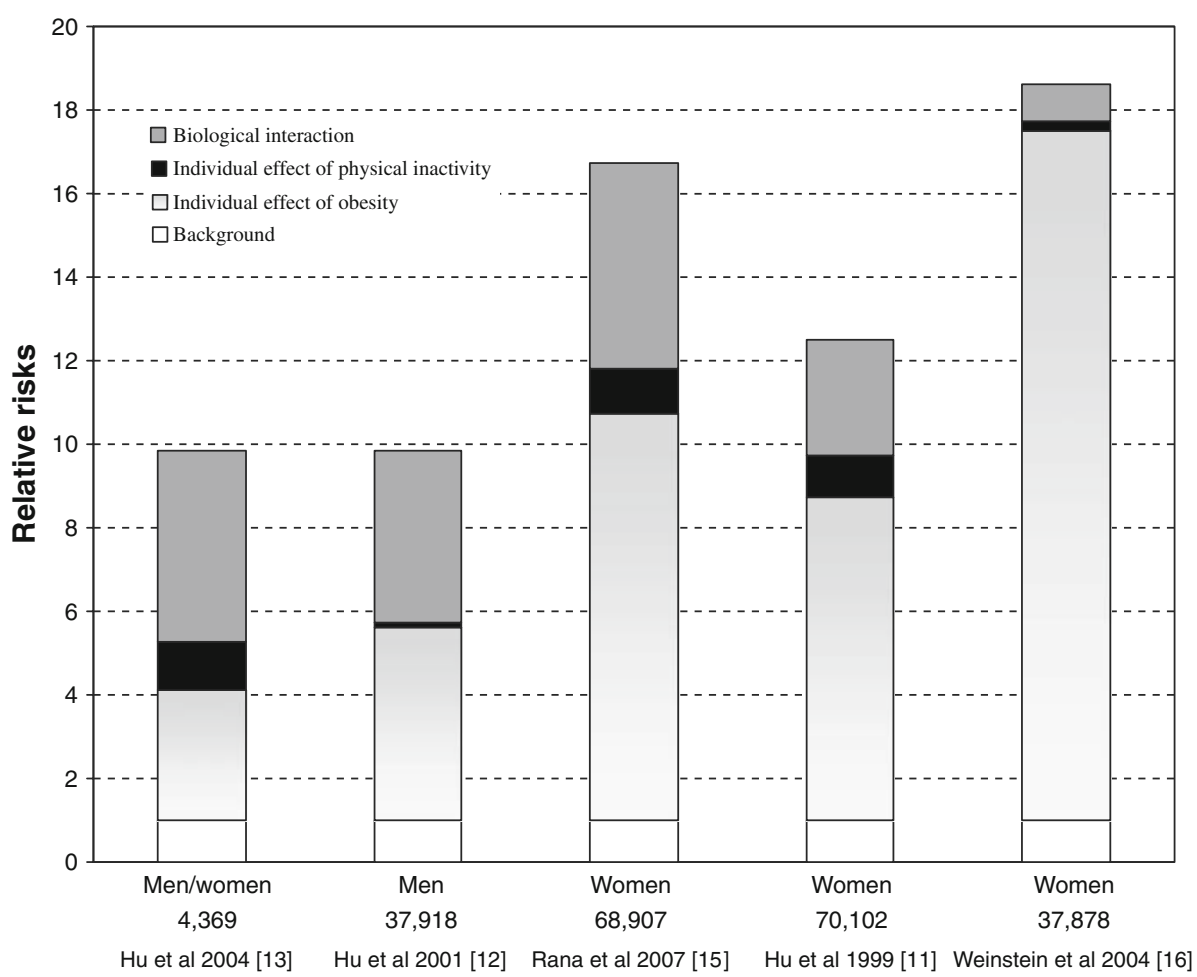

assess biologic interaction [8, 9]. This positive interaction means that the risk of type 2 diabetes in individuals who are both obese and physically inactive is more than what would be expected if the effect of obesity and physical inactivity are summed. So if obesity or physical inactivity is (partly) prevented, this will not only reduce the cases of type 2 diabetes that are caused by one of the factors but also the cases that are caused by the interaction of the two factors. In addition, we found that the proportion of diabetes cases that could be attributed to biological interaction was higher than the proportion that could be attributed to the independent effect of physical inactivity. This indicates that physical inactivity mainly interacts with obesity to cause diabetes, instead of its independent effect, which makes it even more important to increase physical activity.

Interaction is often assessed by including a product (or interaction) term in a regression model. If this model is a multiplicative model, such as logistic regression or Cox proportional hazards model, the product term assesses interaction on a multiplicative scale. We found inconsistent results regarding interaction on a multiplicative scale; in some studies this interaction was positive, while in others it was negative. This means that the risk of type 2 diabetes in individuals who are both obese and physically inactive is more (in case of positive interaction) or less (in case of negative interaction) than what would be expected if the 
effect of obesity and physical inactivity are multiplied. This statistical interaction has no direct relevance to biological interaction [24, 25], but only refers to which statistical model fits best.

Interestingly, six of the eight studies that we included in our review, presented individual and joint effects of obesity and physical inactivity using one reference category (normal weight and high level of physical activity). This way of presenting has been recommended [26-28] because such reporting allows readers to calculate interaction on an additive as well as on a multiplicative scale. In a recent study, it was shown that only $10 \%$ of observational studies use this method of presentation [27]. None of the included studies in our review calculated interaction on an additive scale. This is in line with results of a review where only 3 out of 225 published epidemiological studies mentioned the additive scale for the interpretation of interaction [27].

A limitation of our study is that we were not able to calculate confidence intervals around the estimates of interaction because the included studies did not provide enough information. We also could not calculate a pooled estimate of interaction because of lack of information. Another limitation is that inconsistent adjustment and over-adjustment for confounders could have increased the heterogeneity of relative risks across studies, which might also have increased the variability of the estimates of interaction.

In this review of eight studies that investigated the interaction between obesity and physical inactivity on the risk of type 2 diabetes, we found evidence for positive interaction on an additive scale. This means that prevention of either obesity or physical inactivity, not only reduces the risk of diabetes by taking away the independent effect of this factor but also by preventing the cases that are caused by the interaction between both factors. Furthermore, this review clearly showed that results can differ depending on what method is used to assess interaction. Researchers should be aware of these different methods and should motivate why they choose a certain method to assess interaction.

Acknowledgments We thank Dr. C.M. Schooling from Department of Community Medicine, Hong Kong University, for her useful suggestions on a draft version of the manuscript.

Open Access This article is distributed under the terms of the Creative Commons Attribution Noncommercial License which permits any noncommercial use, distribution, and reproduction in any medium, provided the original author(s) and source are credited.

\section{Appendix}

In linear regression model, $Y$ is the continuous outcome due to risk factors $\mathrm{A}$ and $\mathrm{B}$, and the interaction in an additive scale $\left(\mathrm{INT}_{\mathrm{A}}\right)$ is assessed by adding a product term $\mathrm{A} \times \mathrm{B}$. The regression coefficient of the product term $\left(\beta_{\mathrm{A} \times \mathrm{B}}\right)$ is departure from additivity. In logistic regression model, $\mathrm{OR}_{\mathrm{AB}}$ is the odds due to risk factors $\mathrm{A}$ and $\mathrm{B}$, and the interaction in a multiplicative scale $\left(\mathrm{INT}_{\mathrm{M}}\right)$ is also constructed by adding a product term $\mathrm{A} \times \mathrm{B}$ but after exponential transformation. Often in epidemiological research, odds ratios (OR) or hazard ratios (HR) derived from logistic regression model or Cox proportional hazard model can be used as relative risks (RR) [29, 30]. Therefore, the relative risk due to biological interaction (RERI) can be assessed by disease ratios directly from logistic regression or Cox proportional hazard model. The characteristics of the different interaction models are given in the Table 3.

Table 3 The characteristics of the different interaction terms

\begin{tabular}{|c|c|c|c|}
\hline & $\mathrm{INT}_{\mathrm{A}}$ & $\mathrm{INT}_{\mathrm{M}}$ & RERI \\
\hline $\begin{array}{l}\text { Statistical } \\
\text { model }\end{array}$ & Linear regression model & $\begin{array}{l}\text { Logistic regression or } \\
\text { Cox proportional hazard model }\end{array}$ & $\begin{array}{l}\text { Logistic regression or } \\
\text { Cox proportional hazard model }\end{array}$ \\
\hline $\begin{array}{l}\text { Interpretation } \\
\text { way }\end{array}$ & A product term $\mathrm{A} \times \mathrm{B}$ & A product term $\mathrm{A} \times \mathrm{B}$ & Additive relative risks \\
\hline$\beta$ of interaction & $\beta_{\mathrm{A} \times \mathrm{B}}$ & $\beta_{\mathrm{A} \times \mathrm{B}}$ & - \\
\hline $\begin{array}{l}\text { Interaction } \\
\text { model }\end{array}$ & Additive scale & Multiplicative scale & Additive scale \\
\hline Outcome & $\begin{array}{l}\text { The change of absolute values of the } \\
\text { continuous outcome }(Y)\end{array}$ & $\mathrm{OR}, \mathrm{HR}$ or $\mathrm{RR}^{\mathrm{a}}$ & $\mathrm{RR}^{\mathrm{a}}$ \\
\hline Formula & $\begin{array}{l}Y=\beta_{\mathrm{A}} \cdot \mathrm{A}+\beta_{\mathrm{B}} \cdot \mathrm{B}+\beta_{\mathrm{A} \times \mathrm{B}} \cdot \mathrm{AB} \\
\mathrm{INT}_{\mathrm{A}}=Y-\left(\beta_{\mathrm{A}} \cdot \mathrm{A}+\beta_{\mathrm{B}} \cdot \mathrm{B}\right)=\beta_{\mathrm{A} \times \mathrm{B}} \cdot \mathrm{AB}\end{array}$ & $\begin{array}{l}\mathrm{OR}_{\mathrm{AB}}=\mathrm{e}^{\beta_{\mathrm{A}}+\beta_{\mathrm{B}}+\beta_{\mathrm{A} \times \mathrm{B}}}=\mathrm{e}^{\beta_{\mathrm{A}}+\mathrm{B}_{\mathrm{B}}} \cdot \mathrm{INT}_{\mathrm{M}} \\
\mathrm{INT}_{\mathrm{M}}=\mathrm{e}^{\beta_{\mathrm{A} \times \mathrm{B}}}=\frac{\mathrm{OR}_{\mathrm{AB}}}{\mathrm{OR}_{\mathrm{A}} \cdot \mathrm{OR}_{\mathrm{B}}}\end{array}$ & $\begin{aligned} & \approx \mathrm{e}^{\beta_{\mathrm{A}}+\beta_{\mathrm{B}}+\beta_{\mathrm{A} \times \mathrm{B}}}-\mathrm{e}^{\beta_{\mathrm{A}}}-\mathrm{e}^{\beta_{\mathrm{B}}}+1\end{aligned}$ \\
\hline $\begin{array}{l}\text { Positive } \\
\text { interaction }\end{array}$ & $\beta_{\mathrm{A} \times \mathrm{B}}>0$, then $\mathrm{INT}_{\mathrm{A}}>0$ & $\beta_{\mathrm{A} \times \mathrm{B}}>0$, then $\mathrm{INT}_{\mathrm{M}}>1$ & RERI $>0$ \\
\hline No interaction & $\beta_{\mathrm{A} \times \mathrm{B}}=0$, then $\mathrm{INT}_{\mathrm{A}}=0$ & $\beta_{\mathrm{A} \times \mathrm{B}}=0$, then $\mathrm{INT}_{\mathrm{M}}=1$ & $\mathrm{RERI}=0$ \\
\hline $\begin{array}{l}\text { Negative } \\
\text { interaction }\end{array}$ & $\beta_{\mathrm{A} \times \mathrm{B}}<0$, then $\mathrm{INT}_{\mathrm{A}}<0$ & $\beta_{\mathrm{A} \times \mathrm{B}}<0$, then $\mathrm{INT}_{\mathrm{M}}<1$ & RERI $<0$ \\
\hline
\end{tabular}

${ }^{\mathrm{a}}$ Often, $\mathrm{RR} \approx \mathrm{OR}$ or $\mathrm{HR}$ 


\section{References}

1. Bjorntorp P. Metabolic implications of body fat distribution. Diabetes Care. 1991;14(12):1132-43.

2. Boden G. Role of fatty acids in the pathogenesis of insulin resistance and NIDDM. Diabetes. 1997;46(1):3-10.

3. Lewis GF, Carpentier A, Adeli K, et al. Disordered fat storage and mobilization in the pathogenesis of insulin resistance and type 2 diabetes. Endocr Rev. 2002;23(2):201-29.

4. McGarry JD. Banting lecture 2001: dysregulation of fatty acid metabolism in the etiology of type 2 diabetes. Diabetes. 2002;51 (1):7-18.

5. LaMonte MJ, Blair SN, Church TS. Physical activity and diabetes prevention. J Appl Physiol. 2005;99(3):1205-13.

6. Church TS, LaMonte MJ, Barlow CE, et al. Cardiorespiratory fitness and body mass index as predictors of cardiovascular disease mortality among men with diabetes. Arch Intern Med. 2005; 165(18):2114-20.

7. Sui X, Hooker SP, Lee IM, et al. A prospective study of cardiorespiratory fitness and risk of type 2 diabetes in women. Diabetes Care. 2008;31(3):550-5.

8. Rothman KJ, Greenland S. Concepts of interaction. In: Modern epidemiology. 2nd ed. Philadelphia: Lippincott-Raven Publishers. Philadelphia: Lippincott-Raven Publishers; 1998.

9. Rothman KJ. Epidemiology: an introduction. New York: Oxford University Press; 2002.

10. Knol MJ, van der Tweel I, Grobbee DE, et al. Estimating interaction on an additive scale between continuous determinants in a logistic regression model. Int J Epidemiol. 2007;36(5):1111-8.

11. Hu FB, Sigal RJ, Rich-Edwards JW, et al. Walking compared with vigorous physical activity and risk of type 2 diabetes in women: a prospective study. JAMA. 1999;282(15):1433-9.

12. Hu FB, Leitzmann MF, Stampfer MJ, et al. Physical activity and television watching in relation to risk for type 2 diabetes mellitus in men. Arch Intern Med. 2001;161(12):1542-8.

13. Hu G, Lindstrom J, Valle TT, et al. Physical activity, body mass index, and risk of type 2 diabetes in patients with normal or impaired glucose regulation. Arch Intern Med. 2004;164(8):892-6.

14. Kriska AM, Saremi A, Hanson RL, et al. Physical activity, obesity, and the incidence of type 2 diabetes in a high-risk population. Am J Epidemiol. 2003;158(7):669-75.

15. Rana JS, Li TY, Manson JE, et al. Adiposity compared with physical inactivity and risk of type 2 diabetes in women. Diabetes Care. 2007;30(1):53-8.
16. Weinstein AR, Sesso HD, Lee IM, et al. Relationship of physical activity vs body mass index with type 2 diabetes in women. JAMA. 2004;292(10):1188-94.

17. Hu FB, Manson JE, Stampfer MJ, et al. Diet, lifestyle, and the risk of type 2 diabetes mellitus in women. $\mathrm{N}$ Engl $\mathrm{J}$ Med. 2001;345(11):790-7.

18. Meisinger $\mathrm{C}$, Lowel $\mathrm{H}$, Thorand $\mathrm{B}$, et al. Leisure time physical activity and the risk of type 2 diabetes in men and women from the general population. The MONICA/KORA Augsburg cohort study. Diabetologia. 2005;48(1):27-34.

19. Ross R, Dagnone D, Jones PJ, et al. Reduction in obesity and related comorbid conditions after diet-induced weight loss or exercise-induced weight loss in men. A randomized, controlled trial. Ann Intern Med. 2000;133(2):92-103.

20. Ross R, Janssen I, Dawson J, et al. Exercise-induced reduction in obesity and insulin resistance in women: a randomized controlled trial. Obes Res. 2004;12(5):789-98.

21. Dekker MJ, Lee S, Hudson R, et al. An exercise intervention without weight loss decreases circulating interleukin-6 in lean and obese men with and without type 2 diabetes mellitus. Metabolism. 2007;56(3):332-8.

22. Lee S, Kuk JL, Davidson LE, et al. Exercise without weight loss is an effective strategy for obesity reduction in obese individuals with and without type 2 diabetes. J Appl Physiol. 2005;99(3):1220-5.

23. Horowitz JF. Exercise-induced alterations in muscle lipid metabolism improve insulin sensitivity. Exerc Sport Sci Rev. 2007;35(4): 192-6.

24. Ahlbom A, Alfredsson L. Interaction: a word with two meanings creates confusion. Eur J Epidemiol. 2005;20(7):563-4.

25. VanderWeele TJ. Sufficient cause interactions and statistical interactions. Epidemiology. 2009;20(1):6-13.

26. Kaufman JS. Interaction reaction. Epidemiology. 2009;20(2): 159-60.

27. Knol MJ, Egger M, Scott P, et al. When one depends on the other: reporting of interaction in case-control and cohort studies. Epidemiology. 2009;20(2):161-6.

28. Botto LD, Khoury MJ. Commentary: facing the challenge of gene-environment interaction: the two-by-four table and beyond. Am J Epidemiol. 2001;153(10):1016-20.

29. Li R, Chambless L. Test for additive interaction in proportional hazards models. Ann Epidemiol. 2007;17(3):227-36.

30. Skrondal A. Interaction as departure from additivity in casecontrol studies: a cautionary note. Am J Epidemiol. 2003;158(3): 251-8. 